\title{
Metaleptic Parabasis, or The Fine Art of High Jumping · Mark Axelrod
}

AS WE KNOW, in the history of high jumping there have been three accepted forms: the Eastern Roll, the Western Roll, and the Fosbury Flop (the last of which has erroneously been labelled Stonesian). Of the three, the first has had limited success at higher heights and the last has been considered, and rightly so as we shall see, a Gogolian manifestation of the second, which, over the years, has been considered the traditional method of Parabasis, (here, of course, Parabasis being an extension if you will of the art of High Jumping).

The key factors in any type of Parabasis are (1) spring (which accounts for approximately $90 \%$ of the height obtained) and (2) layout or rotation over the bar. Likewise, the interrelationship between spring and rotation is intimately connected with take-off and take-off approach. Obviously, the running approach to the bar is the approach of choice since it improves vertical lift and provides optimum horizontal motion for clearance. The basic technique for Parabasis is simple: a jumper projects himself into the air by moving his legs in such a fashion that he exerts a force against the ground larger than that supporting his weight; the reaction to this additional force propels him upward. Good high jumpers employ forceful, fast, and long take-off thrusts which translate into effective lift and

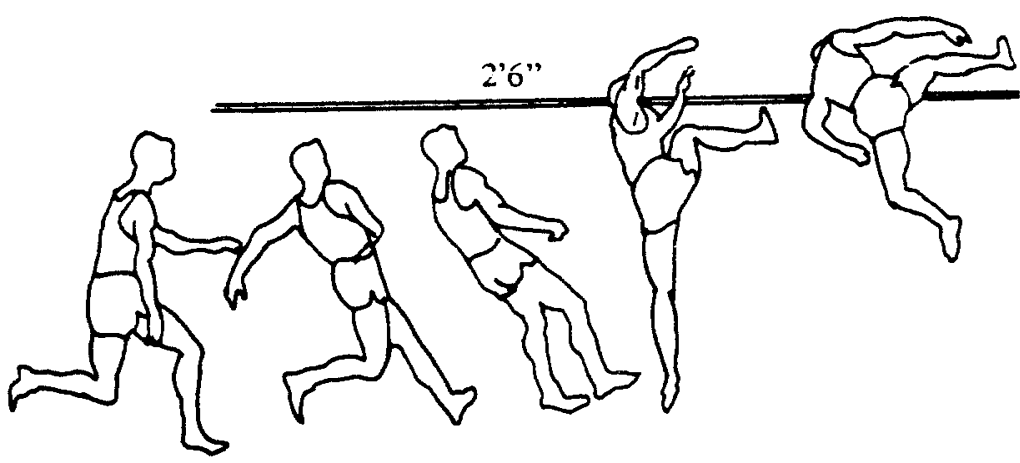

rotation. As we will see, the best Parabasists are take-off conscious; poor ones are anxious to get over the bar. 
As we stated earlier, the Eastern method of Parabasis, an essentially Greek technique, was the accepted mode of high jumping up until the innovations of Cervantes. Cervantes took the basic concepts of the sport, formulated by the early Greek jumpers (most notably Aristotle and Socrates) and, with the help of his coach Cid Hamet Benengeli, refined the old form into a new one which, as we have seen, has come to be called the Western Roll or Metaleptic Parabasis.

Cervantes improved on this technique by viewing the bar in multiple perspectives, thus realizing that he could approach it from almost any angle rather than just one. The obvious problem here is a rotational one; that is, with multiple approaches one might expect a decrease in spring due to the jumper's lack of consistent form, which would, therefore, be followed by a concomitant decrease in rotational ability. But by checking linear motion, transferring angular momentum and by thrusting eccentrically to the center of gravity, Cervantes found that a constant angular momentum could be developed. Here is where Cervantes was at his best. His skill lay in the fact that he could approach the bar from either the right or the left side without a decrease in take-off speed and without any nega-

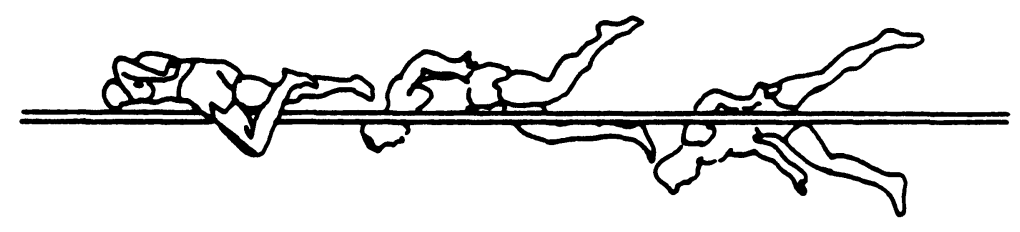

tive effect to his rotation (though some critics have called his rotation hyperbole, it is not as obvious as, say, Voltaire).

Taking an acute, but parallel approach to the bar, Cervantes' spring was often looked at as burlesque because of its mock of the traditional Eastern approach to high jumping; however, the rotation of his body and subsequent Parabasic excellence led most viewers to appreciate the efficacy of Cervantes' technique.

As Coach Benengeli once said, "Es verdad. Miguel's heights shall not be achieved for at least several hundred years." Little did Benengeli know how verdad he would be, for Cervantes' high jumping techniques have been seminal. Those who have followed him (Quevedo, Sterne, Fielding, Stendhal, Flaubert, Borges, et cetera, et cetera) have more or less copied the same pattern. However, Cervantes' approach is of such magnitude 
that most who have followed, even if they could pass the same heights, have generally lost to Cervantes on fewer misses.

It was not until the nineteenth century Russian high jumpers that we found another Parabasist with an equally innovative approach. Gogol's approach was eccentric in that he refused any "naturalistic" attempt at clearing the bar. Gogol compromised Cervantes' techniques with those of Voltaire (a competent but not great jumper) thus creating what his coach Akaky Akakievich once called "negative hyperbole." Unlike Cervantes or

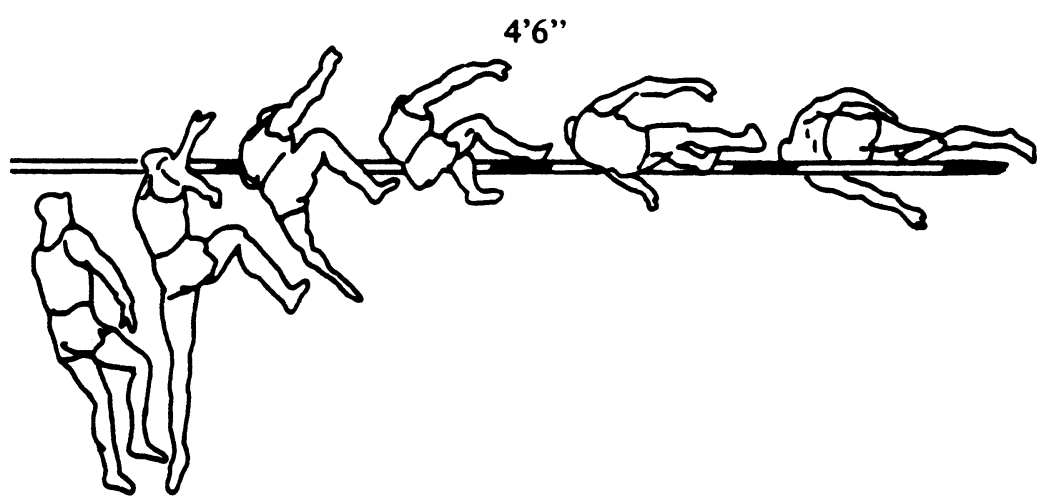

Voltaire, Gogol was actually capable of switching his forward momentum at the last moment, thus altering his rotation over the bar in the opposite direction to his jump. This technique, of course, predates both the Fosbury Flop as well as the Stonesian derivative.

The difficulties of such an approach are obvious. Up to that time, there had been no other jumper who could translate forward momentum to backward momentum and still clear competitive heights. But Gogol used other methods as well. Not only did he use negative hyperbolic rotation, but he also used, on occasion, a rather "supernatural" method known only to him. The first time he used such a method was during the annual Nevsky Avenue Track Meet. At that time, Gogol had passed every height up to 6' 22". Then, he took his spot, made his approach (a run by the way which looked very similar to Valery Brúmel), went into his negative hyperbolic rotation, and cleared the bar except for the heel of his right foot. What was not believable, however, was that his foot actually passed "through" the bar without dislodging it. The audience was dumbfounded as were the judges who could not believe what they had seen. Gogol jumped out of the pit as if there were nothing wrong, while Akakievich, 


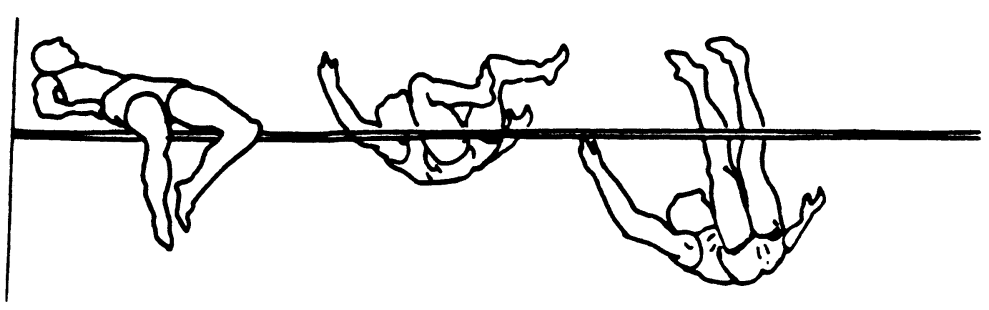

still wearing his tattered overcoat, smiled sheepishly at the crowd as he hobbled over and handed Gogol his sweatpants.

Needless to say, his techniques are at times occult since he can approach the bar acutely, obliquely, or obtusely (not to mention abstrusely) and still get the same vertical lift. Though Cervantes approached the bar from different angles, he could not translate his forward momentum in the same manner as Gogol. Many who had seen Gogol jump called his Parabasis, "oxymoronic," but those who followed his career closely were aware of his true abilities and knew him as a very serious high jumper.

At the turn of the century we find another high jumper with both the fundamental skills of Cervantes and the eccentric skills of Gogol. One wouldn't have thought that Kafka, slim, short, and amuscular, could possibly have been capable of leaping to the heights that he did; but using many of Benengeli's techniques (essentially those which seemed comedic) as well as some of Akakievich's (almost surrealistic), Kafka was able to combine the best of both into another which was different from either.

Not only was Kafka's approach alike but dissimilar, but it was also an approach of "unnervation." Though an excellent Parabasist, Kafka's basic

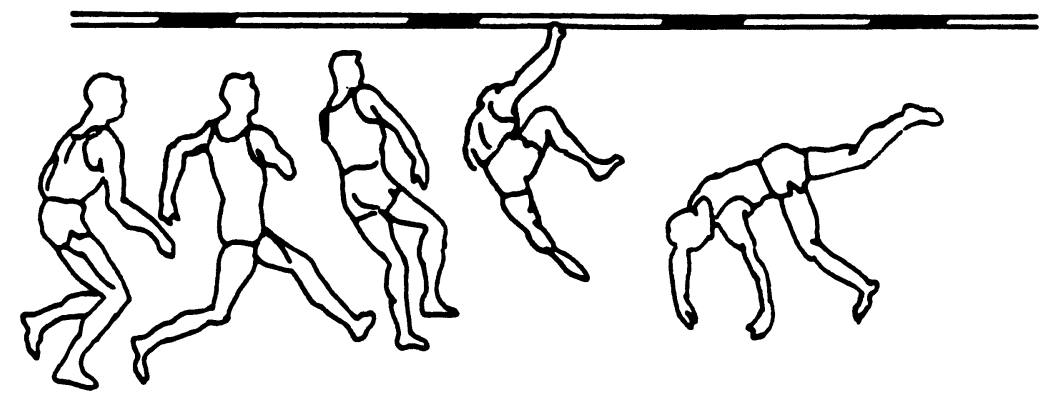


idea was to unnerve his competition. As his coach/pet Gregor Samsa once said, "Franz is not concerned with self-importance. One meet means no more than another, nor does one jump mean more than another. Franz attempts to win before the meet begins by out-psyching his opponents." That was true on more than one occasion. Kafka was prone to, as he did in the European championships, walk to the bar, stare at it, return and make his approach, then jump under the bar and into the pit. No doubt the judges were at odds with themselves as to what to do especially when Samsa demanded that the jump count since it was never stated whether Franz had to "pass over or under the bar" only that "he clear it." Generally that confused the officials even more and though they ultimately ruled against the request, they usually allowed Kafka another attempt, which, more often than not, disrupted the competition's concentration.

Kafka was, as most coaches will acknowledge, the last of the truly innovative twentieth-century high jumpers. Not only could he equal the heights of Cervantes and surpass the heights of Gogol, but his style, which has yet to be understood, can hardly be imitated. Actually, the only high jumper who might challenge Kafka's high jump record is writing this paper and he will have to stop since he is incapable of jumping higher than

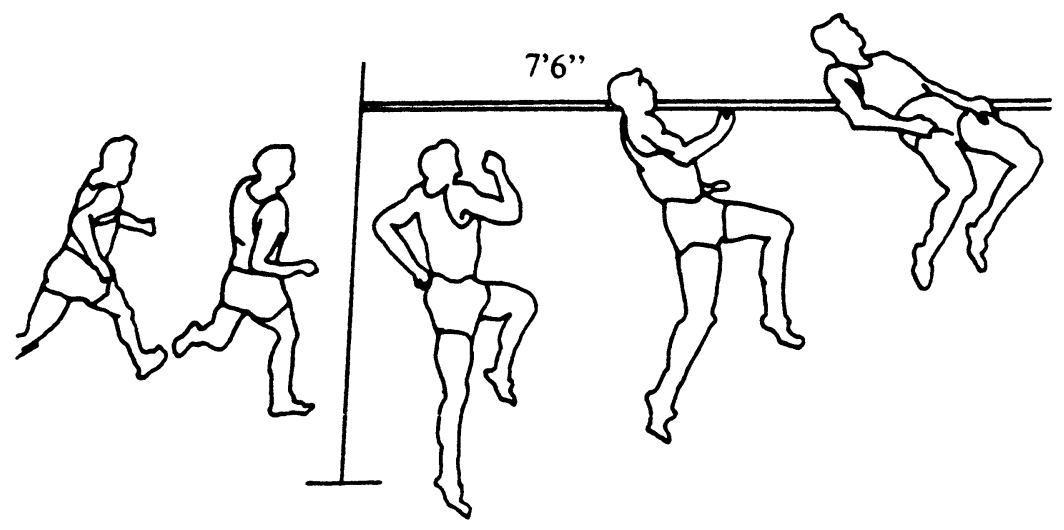

the lowest point on this page. He has, over the years, been able to increase his spring; however, his biggest problem has been clearing the bar with his trailing leg; but, as we all know, endings have been difficult for all leapers.

To make some cogent comment on the protean qualities of irony after reading this paper would be tantamount to making a cogent comment on the efficacy of paper as a medium for words; however, cogent comments 
aside, the strength of irony lies in its nubile ability to disavow the beginning for the end, to construct the deconstruction and then, to laugh at itself for the attempt. 